\title{
Systematic review of qualitative research on coercive treatment Stefan Priebe
}

\author{
Address: Unit for Social and Community Psychiatry, Queen Mary, University of London, Academic Unit, Newham Center for Mental Health, \\ Cherry Tree Way, Glen Road, London, E13 8SP, UK \\ from WPA Thematic Conference. Coercive Treatment in Psychiatry: A Comprehensive Review \\ Dresden, Germany. 6-8 June 2007 \\ Published: 19 December 2007 \\ BMC Psychiatry 2007, 7(Suppl I):S56 doi:10.1 I86/I47I-244X-7-SI-S56
}

This abstract is available from: http://www.biomedcentral.com/I47I-244X/7/SI/S56

(c) 2007 Priebe; licensee BioMed Central Ltd.

This paper reports findings of a review of qualitative studies exploring patients' experiences of involuntary hospital treatment. Thematic analysis was used to synthesize emerging issues from different studies. Only five studies with a total sample of 54 patients fulfilled the inclusion criteria of the review. Main themes in the studies were a) patients' perceived autonomy and participation in clinical decision-making, b) the extent to which they felt cared for and c) their sense of self-respect. In all these areas both negative and positive aspects of involuntary admissions and treatments were found. However, studies are also characterised by major methodological shortcomings. Thus, the potentials of qualitative research in this area have not yet been fully utilized. 